\title{
Research about NG-PDT Influence to Thymus- Dependent Lymphocyte Subpopulation from Peripheral Blood of Bronchogenic Carcinoma
}

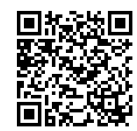

\author{
Linlin $\mathrm{Xu}^{1 *}$, Jing Liang ${ }^{2}$ and Lei Gong ${ }^{3}$ \\ ${ }^{1}$ Department of Graduate School of Medicine, Chiba University, Chiba, Japan \\ ${ }^{2}$ Department of the People's Hospital of Huaiji, China \\ ${ }^{3}$ Department of QiaoKang Tumor Hospital of Jinan University, China
}

Submission: August 30, 2018; Published: September 17, 2018

*Correspondence Address: Linlin Xu, Department of Graduate School of Medicine, Chiba University, Chiba, Japan;

Email Id: xulinlin9977@163.com

\begin{abstract}
Introduction: To research about PDT influence to thymus-dependent lymphocyte subpopulation from peripheral blood of bronchogenic carcinoma.

Method: Taking forty patients as study objects who suffering the bronchogenic carcinoma, the researchers use semi-conductive laser therapy apparatus (made in China) to irradiate the diseased region, and then observe the changed information of thymus-dependent lymphocyte subpopulation from peripheral blood during pre-therapy and post-treatment by immunohistochemical techniques of streptavidin-peroxidase (abbreviation: S-P method).
\end{abstract}

Result: The level of some medical data in pre-therapy is higher than the data in post-therapy (like CD3+, CD4+, CD8+, CD4+/CD8+, CD45RA+, the absolute value of CD45RA+, the absolute value of CD45RA+ and CD45RA+/RO+); And the level of CD45RO+ $(\mathrm{P}<0.05)$ is lower than the data in pre-therapy.

Conclusion: Photodynamic therapy provides the technical support with clinic treatment for bronchogenic carcinoma through immune adjustment to enhance the immunologic function.

Keywords: Photodynamic Therapy; Bronchogenic Carcinoma; T Lymphocyte Subpopulation (Pb)

\section{Introduction}

The theory of Photodynamic Therapy (PDT) depends on biological-photodynamic sensitization [1], which has high tissue specificity, low virulence and no immunosuppression. The chemical reaction of luminescence is widely applied to clinical therapy for the reason that it would not take interference into surgical operation, radiotherapy, and chemotherapy, and besides this therapy could be taken repeatedly in limited time of therapy. Because the progression of tumor, especially malignancy, is closely related to immunologic function, it is necessary to discuss the medical effect of immunologic function that photodynamic therapy caused. The key point in this paper is aim to research the medical change of thymus-dependent lymphocyte subpopulation (PB) which the photodynamic therapy caused.

\section{Information and method}

\section{General Information}

Take forty patients who were suffering bronchogenic carcinoma as study objects, among them there are 26 males and
14 females; The ages are between $47 \mathrm{~s}-75 \mathrm{~s}$, and the average age is 60.11 \pm 8.09 . Pathological classification: 29 cases for lung cancer of gland cell, 11 cases for squamous carcinoma; TNM staging: 7 cases for II stage, 22 cases for III stage, 11 cases for IV stages.

\section{Inclusion criteria}

i. $\quad$ Age $\leq 75 \mathrm{~s}$.

ii. No taking any inhibitor medicine at pre-therapy.

iii. No infectious diseases within one month at pre-therapy.

iv. No fever.

v. No taking blood transfusion within three months at pre-therapy or taking operation (including post operation) under $400 \mathrm{ml}$ (or without blood transfusion).

vi. No symptomatic infection at post-therapy.

vii. The one who sign his name on the informed consent 


\section{Cancer Therapy \& Oncology International Journal}

\section{Exclusion criteria:}

viii. Age $>75 \mathrm{~s}$; with history of immunological diseases; getting complication like infection.

\section{Therapeutic Method}

Before taking therapy, all the patients take blood sampling through cubital vein to check $\mathrm{T}$ lymphocyte subpopulation on morning with empty stomach. And then $2 \mathrm{mg} / \mathrm{kg}$ photosensitizer was injected into vein firstly. After 48 hours, 630nm (wave length) laser was irradiated into nidus under endoscope and photodynamic doses was $200 \mathrm{~J} / \mathrm{cm}$. The range of irradiation should be $1-2 \mathrm{~cm}$ over the superior and inferior margin of nidus. According to the condition of the disease, the same drug should be injected after 72 hours and 96 hours and reuse the same photodynamic dose [2] several times to take laser radiation.

\section{Detection Method of Thymus-Dependent Lymphocyte Subpopulation}

Take $3 \mathrm{ml}$ peripheral venous blood at pre-therapy and posttreatment from the patients who suffer bronchogenic carcinoma in the morning; take heparin sodium for anticoagulation as standby application; based on the operating instructions, use immunohistochemical techniques of streptavidin-peroxidase (abbreviation: S-P method) strictly, and the reagent was produced by ShenZhen Kebio Company.

\section{Statistical Method}

Analyze the data statistically by software SPSS18.0; Measurement data is showed by $(\bar{x} \pm s)$, verified by ' $t$ ', standard: $\mathrm{P}<0.05$.

\section{Results}

\section{Situation Analysis for Variation of Thymus-dependent Lymphocyte Subpopulation}

The level of $\mathrm{CD} 3+, \mathrm{CD} 4+, \mathrm{CD} 8+$ and $\mathrm{CD} 4+/ \mathrm{CD} 8+$ at posttherapy is higher than the level at pre-therapy $(\mathrm{P}<0.05)$ (Table 1).

Table 1: Comparison for TC Subpopulation at Pre-therapy and Posttherapy $(\bar{x} \pm s)$

\begin{tabular}{|c|c|c|c|c|c|}
\hline Time & Cases(n) & CD3+ & CD4+ & CD8+ & $\begin{array}{c}\text { CD4+/ } \\
\text { CD8+ }\end{array}$ \\
\hline $\begin{array}{c}\text { Pre- } \\
\text { therapy }\end{array}$ & 40 & $55.29 \pm$ & $45.92 \pm$ & $32.17 \pm$ & $1.09 \pm$ \\
\hline $\begin{array}{c}\text { Post- } \\
\text { therapy }\end{array}$ & 40 & 11.20 & 8.73 & 6.53 & 0.29 \\
\hline $\mathrm{t}$ & & $4.71 \pm$ & $55.68 \pm$ & $38.20 \pm$ & $1.66 \pm$ \\
\hline $\mathrm{P}$ & & 0.025 & 0.019 & 0.034 & 0.039 \\
\hline
\end{tabular}

Situation Analysis for Variation of CD45RA+/RO+ at Pre-therapy and Post-therapy

The level of CD45RA+, the absolute value of CD45RA+, the absolute value of CD45RA+ and CD45RA+/RO+ at post-therapy is higher than the level at pre-therapy, the level of CD45RO+ is lower than pre-therapy $(\mathrm{P}<0.05)$ Reference (Table 2$)$.
Table 2: Variation of CD45RA+/RO+ at Pre-therapy and Post-therapy $(\bar{x} \pm s)$.

\begin{tabular}{|c|c|c|c|c|c|}
\hline \multirow[t]{2}{*}{ Time } & $\begin{array}{c}\text { CD45 } \\
\text { RA+ }\end{array}$ & $\begin{array}{c}\mid \mathrm{CD} 45 \\
\mathrm{RA}+\mid\end{array}$ & $\begin{array}{c}\text { CD45 } \\
\text { R+ }\end{array}$ & |CD45RO+| & \multirow{2}{*}{$\begin{array}{c}\text { CD45RA+/ } \\
\text { RO+ }\end{array}$} \\
\hline & (\%) & $(\times 109 / L)$ & (\%) & $(\times 109 / \mathrm{L})$ & \\
\hline \multirow{2}{*}{ Pre } & $49.09 \pm$ & $0.78 \pm$ & $46.37 \pm$ & $0.56 \pm$ & $1.24 \pm$ \\
\hline & 12.03 & 0.22 & 10.22 & 0.27 & 0.50 \\
\hline \multirow{2}{*}{ Post } & $58.78 \pm$ & $1.25 \pm$ & $42.15 \pm$ & $0.98 \pm$ & $1.58 \pm$ \\
\hline & 14.55 & 0.28 & 8.09 & 0.38 & 0.66 \\
\hline $\mathrm{t}$ & 3.991 & 5.271 & 4.209 & 6.215 & 3.285 \\
\hline $\mathrm{P}$ & 0.028 & 0.022 & 0.025 & 0.015 & 0.037 \\
\hline
\end{tabular}

\section{Discussion}

The diagnostic rate of patient with lung cancer on early stage is very low. Most of the patients who go to hospital for treatment are in the middle and advanced stage, so most of the patients miss the optimal cure time. The cancer cell would produce nontumor-specific immune suppressor so that the immune cell could be suppressed extensively, and then immunologic function of the patients would get decay. $\mathrm{CD} 3+$ is representative of total amount of T-lymphocyte; CD4+, which could secrete IL-2IFN- $\gamma$ and could get synergism with $\mathrm{NK}$ cell, is one kind of helper T-lymphocytes. According to practical function, CD8+ could divide into Suppressor T Cell (Ts) and Cytotoxic T Cell (Tc) and it would lead to suppression of immune response [3]. CD4+/CD8+ could be the important indicator for measuring cellular immune function and judging the information of prognosis. NK cell could secrete the cytotoxin straightly so that the tumor cell could be killed. If the activity gets lower, one reason is that the tumor gets progress and another reason is that the tumor gets metastasis. If the specific value gets lower, it means that the immunologic balance gets destroy so that it causes the cellular immune function gets lower.

Photodynamic Therapy is one kind of cold optics reaction, which is consist of photosensitizer, visible light (common laser) and oxygen. The basic action of PDT is biological-photodynamic sensitization which uses the tumor affinity [4] toward Photofrin, to inject into the patients, and then the ground state of tumor cell, where gathered photosensitizer densely, after irradiated by the laser radiation (wave length: $630 \mathrm{~nm}$ ), would translate into sensitized singlet state which would cause chemical reaction with the sounding oxygen subsequently. The research result show that after taking Photodynamic Therapy, some numerical value, like CD3+, CD4+, CD8+, CD4/CD8+, CD45RA+, the absolute value of CD45RA+, the absolute value of CD45RA+ and CD45RA+ / $\mathrm{RO}+$, are all getting distinct variation $(\mathrm{P}<0.05)$. It means that PDT could influence thymus-dependent lymphocyte subpopulation from peripheral blood of bronchogenic carcinoma.

\section{References}

1. Huan Wang, Hui Lin, Jiao Lan, et al. (2010) Clinical significance of peripheral blood $\mathrm{T}$ cell subsets and NK cell detection before and after surgery in patients with primary non-small cell lung cancer. J New clinical medicine in China 3(4): 312-314. 


\section{Cancer Therapy \& Oncology International Journal}

2. Xun Zhang, Fuyuan Zhao, Lianxiang Zhang, et al. (2003) Dynamic study on cellular immune function of lung cancer patients before and after operation. J Chinese journal of lung cancer 6(4): 294-296.

3. Pusheng $\mathrm{Xu}$, Shuben Li (2011) Changes of peripheral blood $\mathrm{T}$ lymphocyte subsets in patients with bronchogenic carcinoma treated by photokinetics. J Guangzhou medicine 42(1): 15-16.
4. Ruiping Zhang, Bingxin Xu, Shelun Wang (2013) Relationship between regulatory $\mathrm{T}$ cells and prognosis in advanced non-small cell lung cancer. J Modern oncology 21(3): 521-524.

\section{Your next submission with Juniper Publishers will reach you the below assets}

- Quality Editorial service

- Swift Peer Review

- Reprints availability

- E-prints Service

- Manuscript Podcast for convenient understanding

- Global attainment for your research

- Manuscript accessibility in different formats ( Pdf, E-pub, Full Text, Audio)

- Unceasing customer service

Track the below URL for one-step submission https://juniperpublishers.com/online-submission.php 